are analogous to disorders of neural encryption. Encryption is a coding system used over the Internet to ensure privacy of communication: ". . . [using] two different decoding keys, one to encipher a message and a different but related one to decipher [it]". "Deciphering requires a separate key, available only to the intended recipient of the message - or, rather, to the recipient's computer" (Gates, 1995, p. 108).

Might first-rank symptoms of schizophrenia be analogues of abnormal encryption code? A few strands of evidence are suggestive. First-rank symptoms of schizophrenia are not well mimicked by static, unifocal structural brain lesions (David, 1994); they are most closely mimicked by distributed disorders of cerebral function (phencyclidine and amphetamine psychoses; metachromatic leukodystrophy). Also, clinically effective antipsychotics induce specific changes in neural firing ('depolarisation block') which are predictive of clinical efficacy (Grace et al, 1997). These changes exhibit a temporal delay, as with clinical response (weeks post-initiation of pharmacotherapy).

First-rate symptoms may be the result of distributed disturbances in neural code. How might these be analogous to disordered encryption? If neural systems relied upon the accurate 'reading' of output from one brain region by another, then an encryption error might lead to: (a) a 'message' failing to reach its (neural) 'destination'; (b) being 'read' by another brain region; (c) being 'misinterpreted' as originating in a false location (the 'false sender'; giving rise to abnormal form); (d) being subject to misreading, message degradation (producing abnormal content); or (e) a failure of the 'message' to reach its original target location, and hence, a failure of modulation of one (target) brain region by another.

Any such theory must provide falsifiable hypotheses: that neuroimaging investigations of patients with (a) first rank symptoms of schizophrenia would reveal disordered functional connectivity (compared with other people with schizophrenia); and (b) that there would be a temporal relationship between abnormal quales and abnormal electroencephalogram signals in the $40 \mathrm{~Hz}$ or Gamma band range (that associated with subjective phenomena, in consciousness).

If conscious phenomena are codes (implying cognitive-neurophysiological monism), then the medium really is the message.
Davld, A. S. (1994) The neuropsychology of auditoryverbal hallucinations. In The Neuropsychology of Schizophrenia (ed. A. David \& J. Cutting), pp. 269-3/2. Hove: Lawrence Erlbaum

Gates, B. (1995) The Rood Aheod. London: Viking.

Grace, A., Bunnoy, B. S., Moore, H., et of (1997)

Dopamine-cell depolarization block as a model for the therapeutic actions of antipsychotic drugs. Frends in Neurosciences, 20, 31-37.

S. A. Spence Imperial College School of Medicine, MRC Cyclotron Unit, Hammersmith Hospital, Du Cane Road, London WI2 ONN

\section{Lifetime risk of suicide in affective disorders}

Sir: Inskip et al (1998) propose that we revise the lifetime risk of suicide in patients with affective disorders from $15 \%$ to $6 \%$. We believe that their argument can be taken much further. The reduced estimate followed reanalysis of the results from 27 longterm outcome studies using more sophisticated computerised modelling techniques. The nature of the samples used for this modelling can also be questioned. We have identified the papers included from the references in Harris \& Barraclough's (1997) original paper.

Four-fifths of the samples were restricted to in-patients and were therefore biased towards increased severity. None selected first-episode cases, and only $7 \%$ were first-admission cohorts. All these factors will inflate long-term mortality estimates as they progressively select cases of greater severity and greater risk of recurrence. Less than a quarter of the samples were series from defined catchment areas, increasing the likelihood of selection bias with difficult-to-treat patients referred to tertiary academic centres entering the meta-analysis. Several samples were recruited before drug treatments such as lithium and antidepressants were available and in a few cases even before the use of electroconvulsive therapy was widespread. Suicide rates in the general populations of the countries studied varied widely and are not stable over time (Diekstra, 1989).

We suggest that Inskip et al's expectation of $6 \%$ long-term mortality from suicide should refer to patients from undefined catchment areas with two or more admissions for affective disorder. The longterm suicide rate for a first-admission catchment area cohort (which equates more accurately to the lifetime risk for severe disorder) is likely to be much lower than this. For example Sletten et al (1972) (included in Harris \& Barraclough's (1997) paper) give numbers of suicides related to numbers of previous admissions for a mixed diagnostic sample; those patients with a single admission accounted for only $18 \%$ of suicides. Kessing et al (1998), in a large Danish case register study, describe a median time to readmission of 12.8 years for 17434 patients discharged after their first admission for unipolar depression. Only $38 \%$ had two or more admissions. There are differences between the two samples, but the suicide rate for a first-admission cohort could be several-fold less than for those on subsequent admissions, and therefore much lower than Inskip et al's estimate of $6 \%$.

Dlokstra, R. F. W. (1989) Suicide and attempted suicide: An international perspective. Acto Psychiotrico Scondinovico, 80 (suppl. 354), 1-24.

Harris, E. C. \& Barraclough, B. (1997) Suicide as an outcome for mental disorders. A meta-analysis. British journal of Psychiotry, 170. 205-228.

Kessing, L. V., Anderson, P. K., Mortensen, P. B., it of (1998) Recurrence in affective disorder: 1. Case register study. British journal of Psychiotry, 172, 23-28.

Inakdp, H. M., Harris, E. C. \& Barraclough, B. (199a) Lifetime risk of suicide for affective disorder, alcoholism and schizophrenia. British journol of Psychiatry, 172. 35-37.

Shetten, I. W., Brown, M. L., Evenson, R. C., et of (1972) Suicide in mental hospital patients. Diseoses of the Nervous System. 33, 328-334.

S. Davies East Midlands Centre for Forensic Mental Health. Arnold Lodge, Cordelia close, Leicester LE5 OLE

P. C. Naik University of Birmingham, Lyndon Clinic, Hobs Meadow, Solihull, West Midlands B92 8PW

A. S. Lee Department of Psychiatry, University Hospital, Queen's Medical Centre, Nottingham $\mathrm{NG7} 2 \mathrm{UH}$

\section{Suicide, country of birth and coroners' verdicts}

Sir: Neeleman et al (1997) refer to two of our publications on suicide rates among immigrant groups in England and Wales which were, unavoidably, restricted to suicide verdict deaths. However, in other, more recently published work (Raleigh \& Balarajan, 1992; Raleigh, 1996) not cited in their paper, we have noted that suicide verdicts alone significantly underestimate the number of such deaths and, consistent with Department of Health policy on suicide monitoring (Department of Health, 1997), we have included open verdicts. We 
have, as appropriate, also included other categories of external cause deaths such as accidental poisonings and burns (the latter being of particular relevance for suicides among Asian women). In both these papers, for completeness and consistency crosschecks, we examined suicide verdict data as well. Although extending the definition significantly increases the numbers of suicides, it is important to note that patterns of relative suicide risk across ethnic groups are remarkably consistent in all four of our papers covering national data for the $1970 \mathrm{~s}, 80 \mathrm{~s}$ and $90 \mathrm{~s}$ - in particular, the high risk in young Asian women, and the low risk in Asian men and African-Caribbeans.

The caveats associated with mortality analyses using country of birth as a proxy for ethnicity are acknowledged but unavoidable until ethnic data become available. Until then, these large national data sets are an essential complement to local studies such as that of Neeleman et al. As suicide is a relatively rare event, the former provide a much larger database for robust statistical analysis, while the latter facilitate in-depth investigation not otherwise possible. It is noteworthy that the pattern of high/low suicide risk (i.e. direction of differential risk) across ethnic groups is in fact similar in both Neeleman et al's and our approaches.

Department of thatth (1997) Public Heolth Common Dota Set 1996 (including Health of the Nation indicators). Guildford: National Institute of Epidemiology. University of Surrey.

Nedeman, J., Mak, V. \& Wessely, S. (1997) Suicide by age, ethnic group, coroners' verdicts and country of birth. A three-year survey in inner London. British journal of Psychiotry. 171, 463-467.

Rakigh, Y. S. (1996) Suicide patterns and trends in people of Indian subcontinent and Caribbean origin in England and Wales. Ethnicity ond Heolth. 1, 55-63.

—E Balarajen, R. (1992) Suicide and self-burning among Indians and West Indians in England and Wales. British journal of Psychiotry, 161, 365-368.

V. S. Raldigh National Institute of Epidemiology. University of Surrey, 14 Frederick Sanger Road. The Surrey Research Park. Guildford, Surney GU2 5 YD

\section{Opportunities for psychiatry from genetic findings - some concerns}

Sir: Genetic aspects of psychiatric disorders have been discussed, sometimes quite emotionally, ever since the re-discovery of the Mendelian laws around 1900. The eugenic programmes pursued in Germany during the Nazi regime, but also in other European countries and in the USA, led to deeply rooted concerns about possible misuse of genetic knowledge. The advent of molecular genetics during the past decade has opened up a new avenue of perspectives that has reinforced the ongoing debate. We agree with the opinion expressed in the recent review by Rutter \& Plomin (1997) that the public discussion is sometimes blurred by misconceptions and false hopes associated with genetic findings. However, we are less optimistic than they are that precise genetic knowledge might prevent its abuse. Back in the 1920 s population data gathered by Ernst Rüdin, the major representative of eugenic psychiatry in Germany, suggested that affective and schizophrenic disorders involve multiple recessive genes. Rüdin himself based on these findings favoured sterilisation programmes, whereas his co-workers Hans Luxenburger and Bruno Schulz correctly argued that sterilisation of phenotypes would not be effective in removing these disorders from the population; finally, the German eugenic programmes included about 100000 people with schizophrenia (Weber, 1993).

Hence, it is not calming to read in the paper by Rutter \& Plomin (1997) that "susceptibility genes for mental disorders should not provide the basis for a major [emphasis added] expansion of the grounds for termination of pregnancy". The term major might well be subject to interpretation in the future. In addition, Rutter \& Plomin (1997) chose questionable examples to support their claim that an abuse of genetic knowledge is unlikely. People with Down's syndrome, for example, would be very good targets for eugenic programmes, not because they have inherited their disease but because prenatal diagnosis enables their selective abortion. Moreover, we are not as confident as the authors that "it is most unlikely to be ethically acceptable to terminate a pregnancy on the basis of a disorder that may leave the person functioning well for much of their life" in the light of the estimated 1000000 abortions and infanticides performed in India between 1981 and 1991 due to a genetic variant called female gender (Dasgupta \& Bhat, 1997).

Although Rutter \& Plomin (1997) did an excellent job of describing misconceptions about genetic findings, they may themselves have a misconception about the relationship between science and society. Once science has made its achievements available to society the use or abuse of these achievements depends on interpretation that varies over time and is entirely independent of scientific reasoning. Therefore, abuse of genetic knowledge will not be prevented by eradication of scientific misconceptions, but by clear-cut and generally accepted ethical guidelines that have yet to be established.

Dasgupta, M. \& Bhat, P. N. M. (1997) Fertility decline and increased manifestation of sex bias in India. Populotion Studies, 51, 307-315.

Rutter, M. \& Plomin, R. (1997) Opportunities for psychiatry from genetic findings. British joumol of Psychiotry. 171. 209-219.

Waber, M. M. (1993) Ernst Rüdin: Eine Kritische Biogrophie. Berlin: Springer.

T. Pollmicher, M. M. Weber Max Planck Institute of Psychiatry, Kraepelinstrasse 10, D-80804 Munich, Germany

Authors' reply: Drs Pollmächer and Weber note that the prevention of abuse of genetic knowledge requires the combination of good science and careful detailed consideration of the ethical issues. We agree very strongly and, indeed, have argued for the need to take discussion of the ethical issues further forward (Plomin \& Rutter, 1998).

Plomin, R. \& Rutter, M. (1998) Child development, molecular genetics, and what to do with genes once they are found. Child Development, in press.

M. Rutter, R. Plomin MRC Child Psychiatry Unit, Institute of Psychiatry, De Crespigny Park. London SE5 8AF

\section{Fluoxetine-terfenadine and sexual dysfunction}

Sir: We report a case of recovery of orgasm after terfenadine ingestion in a patient taking the selective serotonin reuptake inhibitor antidepressant, fluoxetine.

A 55-year-old man with a 13-year history of depressive symptoms during the winter months meeting DSM-IV criteria for seasonal affective disorder (American Psychiatric Association, 1994) had been taking fluoxetine every winter for six years. Each year since commencement of the treatment with the selective serotonin reuptake inhibitor antidepressant he had experienced anorgasmia which had recovered spontaneously on discontinuation of the drug. During the last episode, unlike previous years, he continued to take the antidepressant well into the summer months. During this period 